\title{
BRITISH CAST IRON RESEARCH ASSOCIATION
}

\author{
OPEN DAYS
}

$\mathrm{T}$ HE British Cast Iron Research Association, Alvechurch, Birmingham, held two open days on May 28 and 29. The first day was arranged for visits by representatives of member firms and the second day for visitors from other research associations, Government laboratories, universities, technical colleges and local schools.

The president of the Association, Mr. E. Player, inaugurated a new experimental cupola installation. The cupola is a shaft furnace in which metal, coke and fluxes are charged alternately and air is blown through tuyères up the furnace shaft. This furnace is likely to remain the most important melting unit for cast iron in Britain for very many years. The reactions occurring are highly complex and the unit is capable of innumerable variations in design. This experimental installation is on a full industrial scale, has mechanical charging and an extensive stockyard. Use can be made of cold or hot blast, the latter being achieved by means of a separate oil-fired blast heater built with radiation and convection sections. It is expected that air blast temperatures of up to $800^{\circ} \mathrm{C}$. will be achieved in the experimental work. This range of blast temperature is far higher than that on which there is any industrial experience at present. The furnace will melt up to about six tons an hour and the molten metal produced will be disposed of by means of a pig-casting machine. Interchangeable well and melting zone sections have been provided so that the melting-zone profile can be changed and the furnace operated without a refractory lining in the melting zone and with water cooling. The equipment is fully instrumented so that materials and thermal balances can be accurately computed.

Dr. J. G. Pearce, formerly director of the Association, opened a new laboratory block to be devoted solely to study of fume and dust in iron foundries and its elimination. This laboratory has a large experimental hall covered by a gantry crane, and is equipped for full-scale studies of the various dust extraction and ventilation problems which arise in iron foundries. There is also a dust-estimation laboratory with a comprehensive range of instruments for sampling industrial dusts. Estimation of the free silica content of collected dusts is carried out by X-ray diffraction. Demonstrations were made of various devices developed by the Association for the control of dust produced during the manufacture of iron castings.

In the chemical analytical laboratory the most important display dealt with the application of liquid/liquid solvent extraction and the removal of iron by extraction as chloride, and the acetylacetone complex was demonstrated. In connexion with slag analysis, the extraction of heavy metals as diethyldithiocarbamate complexes is being applied to the determination of aluminium. Another important display in this laboratory dealt with the determination of trace elements. For the determination of aluminium in cast iron the element is separated as the cupferron complex after removal of interfering elements by extraction with diethyldithiocarbamate and chloroform. The separation of cobalt, copper, lead and bismuth was also illustrated. The determinations were completed by cathode ray polarography or spectrophotometry. The demonstration of special methods of analysis was augmented by the display of a cathode-ray polarograph modified by the British Cast Iron Research Association to improve its utility and a spectrophotometer modified for single beam recording spectrophotometry in the ultra-violet region and for use as a high-sensitivity recording flame spectrophotometer.

The work of the Association not only covers the material cast iron, but also the material used for the moulds into which the molten metal is cast. These are usually clay-bonded silica sands, and the production of castings with good surface finish and free from defects involves consideration of their behaviour when rapidly heated by molten metal. The simulation of this cannot be achieved in the laboratory by heating moulding-sand test pieces in normal laboratory furnaces since, because of the low thermal conductivity of the materials, any organic or carbonaceous materials are destroyed before the test pieces are uniformly heated. These carbonaceous materials contribute in an important manner to the properties of moulding sands and are substantially not destroyed before a casting solidifies in a normal mould. To overcome this difficulty a testing machine using dielectric heating has been developed which enables sand test pieces to be rapidly and uniformly heated to any desired temperature. Load/deformation curves can be automatically recorded when the test piece has reached the required temperature. One such unit has now been thoroughly tested and an attempt is being made to build similar equipment using a higher frequency and greater power input for still more rapid heating rates. The technique should be of interest for the testing of other ceramic and refractory materials at high temperatures, particularly where rapid rates of heating are important.

Cast iron is a complex alloy capable of developing a wide range of properties, depending upon the matter in which solidification proceeds. The properties of grey cast iron are determined by the dispersion of the graphite phase which originates at a eutectic transformation during solidification. The displays indicated that the solidification of this eutectic had received detailed study in terms of nucleation and growth. It appears that elements which reduce the interfacial energy between graphite and the melt increase the number of nuclei growing at a given degree of undercooling. Sulphur and hydrogen appear to reduce the rate of growth of the eutectic cells. The technique by which the nucleation of the iron is estimated by means of eutectic cell counting was demonstrated and stereophotomicrographs of the graphite skeleton within each eutectic cell were shown to illustrate the growth mechanism. A special cooling-curve furnace used for solidification studies was also displayed. This employed a molybdenum heating element and was constructed so that there was always a constant temperature difference between the surroundings and the sample during solidification and recalescence. 
The application of the results of the fundamental work on nucleation to practical problems was well illustrated, particularly in connexion with the soundness of iron castings. Increasing the degree of eutectic nucleation increases the tendeney to shrinkage defects, and methods for reducing eutectic nucleation are being tried. The laboratory findings have been well confirmed by industrial trials.

Fundamental work is also proceeding on the interplay of thermal and nucleation effects in the production of chilled castings, and also on the mechanism of solidification of white cast irons in which the eutectic of austenite and iron carbide can appear in various patterns related to the nucleation of the melt and the amount of undercooling before solidification. The detection of eutectic cells in white cast irons has proved difficult and the use of the reflecting polarizing maicroscope has so far proved to be the most useful tool.

The mechanism of the corrosion attack on cast iron in diesel engine waterways has been studied and the special test rig used was demonstrated. Evidence at present shows this to be caused by the accumulation of acidic oxidation products of the glycol in the coolant, the chief of which is formic acid. The formation of formic acid is probably accelerated by the loss of the copper corrosion inhibitor.

The problem of phosphorus in foundry pig iron was illustrated. To a large extent British iron ores of low phosphorus content are exhausted, and foundry pig irons produced from home ores generally contain more than 1 per cent phosphorus. This element has many harmful effects in cast iron when present in such amounts and the Association has just completed an extensive survey of the possibility of utilizing high phosphorus iron ores for the production of low phosphorus foundry pig iron. It has been possible to demonstrate that by top-blowing with oxygen in a rotary Kaldo converter, the phosphorus of phosphoric pig iron can be substantially eliminated and the iron cheaply recarburized.
Cast iron in steam engineering applications is generally limited to temperatures not exceeding $450^{\circ} \mathrm{F}$. The Association has just completed the first part of an investigation showing that this is an unrealistic limitation since almost all cast irons have dimensional stability up to at least $750^{\circ} \mathrm{F}$. Creep tests are in progress to provide additional evidence.

Cast iron is not a truly elastic material. When stressed the strain can be shown to involve a recoverable anelastic component and an irrecoverable component. By a study of the stress/strain curve the latter has been shown to involve true plastic deformation and also a mechanism by which the graphite voids are increased in size. The application of triaxial stress systems by means of mild notches is shown to modify the mechanical properties. Typical results obtained in this investigation were demon. strated.

For many years the Association has been studying the influence of the gaseous elements in cast iron, and the practical implications of this work were illus. trated. In particular, the influence of aluminium in cast iron in causing the decomposition of water vapour, leading to the solution of hydrogen, was emphasized with many industrial examples.

The Association maintains a Foundry Operations Section to provide the iron-founding industry with an advisory service on productivity and working efficiency. Recently, considerable interest has been displayed in a form of time-lapse ciné photography known as 'Memo-motion' and the equipment used and typical results obtained on foundry operations were demonstrated.

The exhibition material was designed to demonstrate that the work of the Association involved largely applied research undertaken specifically in support of the iron-founding industry, its materials, processes, working conditions and productivity. Many examples were given illustrating how the worker in a more or less fundamental field could receive inspiration and ideas by contact with the day-to-day problems of industry.

H. Morrogh

\section{ATOMIC MECHANISMS OF FRACTURE}

A CONFERENCE on "The Atomic Mechanisms of Fracture" was held at Swampscott, near Boston, Massachusetts, during April 12-14, organized by the National Academy of Sciences--National Research Council. More than 400 people attended, including about twenty from overseas, and twentyfive papers were presented.

Although the main emphasis was on the properties of metals, there were a number of papers dealing with non-metallic crystals, and non-crystalline solids. In the last category interest centred on dynamic effects : H. Schardin presented some rather precise results on the measurement of crack velocities in glasses of various compositions which showed that, although it is approximately true that the maximum crack velocity is proportional to the speed of longitudinal elastic waves, there are significant discrepancies which appear to be correlated with the chemical constitution of the material. H. Kolsky discussed the similarities in behaviour of plastics and viscous liquids when subjected to tensile-stress pulses of short duration, caused by the stress waves from an explosion. At the other extreme end of the time- scale, R. J. Charles discussed the dependence upon time of the strength of silicate glasses under static loading. Attributing this to the chemical action of atmospheric water vapour at the tip of a crack, he adduced supporting evidence from the behaviour of crystalline oxides under similar conditions.

In the main field of interest of the conference, it was clear that the complexity of the process of fracture is now agreed. Four types can usefully be distinguished : (1) ductile; (2) brittle; (3) creep; (4) fatigue. It should, however, be emphasized that this is no more than a classification of convenience; each heading probably covers a variety of processes ; and when any particular body changes from one piece into two pieces a selection of these processes may have been involved, according to the conditions of the experiment. An extreme case arises when a crystal of a soft metal draws down, in tension, to a chisel edge or a point. The mechanism, doubtfully included under the general heading of fracture, is the flowing of material away from the developing neck, by single or multiple glide processes. It was suggested that the central, fibrous part of the typical 